\title{
Rochas granulíticas da Suíte Caparaó na região do Pico da Bandeira:
}

\section{embasamento oriental do Orógeno Araçuaí}

\author{
Tiago Amâncio Novo ${ }^{1 *}$, Carlos Maurício Noce ${ }^{1 * *}$, Antônio Carlos Pedrosa-Soares ${ }^{1}$, \\ Gustavo Antonio Pereira Batista ${ }^{1}$
}

1. CPMTC-IGC-UFMG, Belo Horizonte, MG. * Doutorando em Geologia, UFMG.

**In memoriam.

Recebido em 13 de outubro de 2011; aceito em 28 de outubro de 2011

\begin{abstract}
RESUMO: O Pico da Bandeira é o terceiro cume mais alto do Brasil com 2891,98 m de altitude. Localiza-se na Serra do Caparaó, divisa dos estados de Minas Gerais e Espírito Santo. Esta serra tem sido esculpida essencialmente sobre gnaisses e migmatitos de alto grau, ortoderivados, de composição diorítica a granítica, com encraves máficos, da Suíte Caparaó. Estruturalmente, a Serra do Caparaó configura uma lasca tectônica moldada em antiformal de proporções quilométricas, assimétrico, apertado, aproximadamente orientado segundo NNE-SSW, com o flanco oeste parcialmente invertido e charneira marcada por intensa migmatização. As poucas amostras analisadas sugerem rochas cálcio-alcalinas de médio a alto-K, um pouco enriquecidas em terras raras leves em relação a rochas similares do Complexo Juiz de Fora. A Suíte Caparaó, de idade riaciana (ca. 2,19 Ga), pode ser correlacionada ao Complexo Juiz de Fora e constitui uma porção do embasamento sudeste do Orógeno Araçuaí.
\end{abstract}

Palavras-chave: Granulito, Suíte Caparaó, Orógeno Araçuaí

ABSTRACT: GRANULITIC ROCKS FROM THE CAPARAÓ SUITE IN THE PICO DA BANDEIRA REGION: EASTERN BASEMENT OF THE ARAÇUAÍ OROGEN. In Brazil, the third highest mountain peak, with $2891.98 \mathrm{~m}$ high, is called Pico da Bandeira. It is located at Caparaó mountain ridge, along the boundary between Minas Gerais and Espírito Santo states. This ridge has been shaped on the orthoderived, dioritic to granitic, granulitic gneisses and migmatites with mafic enclaves of the Caparaó Suite. The regional structure of the Caparaó ridge is a folded thrust slice, forming a huge antiformal, asymmetric, tight fold roughly oriented to NNE-SSW, with the western limb partially inverted and the hinge marked by intense migmatization. The few analysed samples suggest medium to high-K calc-alkaline signatures, slightly enriched in light rare earth elements in relation to similar rocks of the Juiz de Fora Complex. The Caparaó Suite, Rhyacian in age (ca. 2.19 Ga), can be correlated to the Juiz de Fora Complex and forms part of the southeastern basement of the Araçuaí orogen.

Keywords: Granulite, Caparaó Suite, Araçuaí orogen

\section{1 - INTRODUÇÃO}

O Pico da Bandeira é o terceiro cume mais alto do Brasil com 2.891,98 metros (IBGE, 2004). Em 1859, Dom Pedro II determinou que fosse colocada uma bandeira do Império naquele que, na época, era tido como o ponto mais alto e imponente do Brasil (daí o nome Pico da Bandeira). Este pico encontra-se no Parque Nacional do Caparaó, divisa dos estados de Minas Gerais e Espírito Santo (Fig. 1). A Serra do Caparaó é parte do domínio geomorfológico das Serranias da Zona da Mata Mineira (Gatto et al. 1983), caracterizada por relevos de formas alongadas com escarpas íngremes e topos aguçados, formando um conjunto de serras orientadas a NNE (Fig. 2).

A Serra do Caparaó situa-se na região meridional do Orógeno Araçuaí que, por sua vez, constitui o setor norte da Província Mantiqueira (PedrosaSoares et al. 2001, 2007; Heilbron et al. 2004; Silva et al. 2005). O embasamento do Orógeno Araçuaí é constituído por complexos arqueanos e paleoproterozóicos, retrabalhados em intensidades diversas durante a orogenia brasiliana (Noce et al. 2007a,b). Neste contexto, a Suíte Caparaó representa uma parte do embasamento ortoderivado, de idade riaciana (ca. 2,19 Ga), da região sudeste do Orógeno Araçuaí (Silva et al. 2002, 2005; Noce et al. 2007a,b).

Entretanto, os gnaisses granulíticos esverdeados da Serra do Caparaó já foram motivo de controvérsia. Campo-Neto \& Figueiredo (1990) consideraram estes granulitos como ortoderivados e os incluíram no Complexo Juiz de Fora, de idade paleoproterozóica. Por outro lado, Söllner et al. (1991) e Seidensticker \& Wiedemann (1992) os interpretaram como rochas paraderivadas de idade brasiliana.

Contudo, a idade riaciana (ca. 2,19 Ga) da cristalização dos protólitos magmáticos dos gnaisses granulíticos da Serra do Caparaó ficou demonstrada pela datação U-Pb SHRIMP obtida por Silva et al. (2002, 2005 e este volume), assim como sua natureza ortoderivada foi também constatada nos estudos realizados no âmbito dos contratos UFMGCPRM-Programa Geologia do Brasil para o mapeamento geológico da região (Horn et al. 2006, Noce et al. 2007a, Novo et al. 2010). 


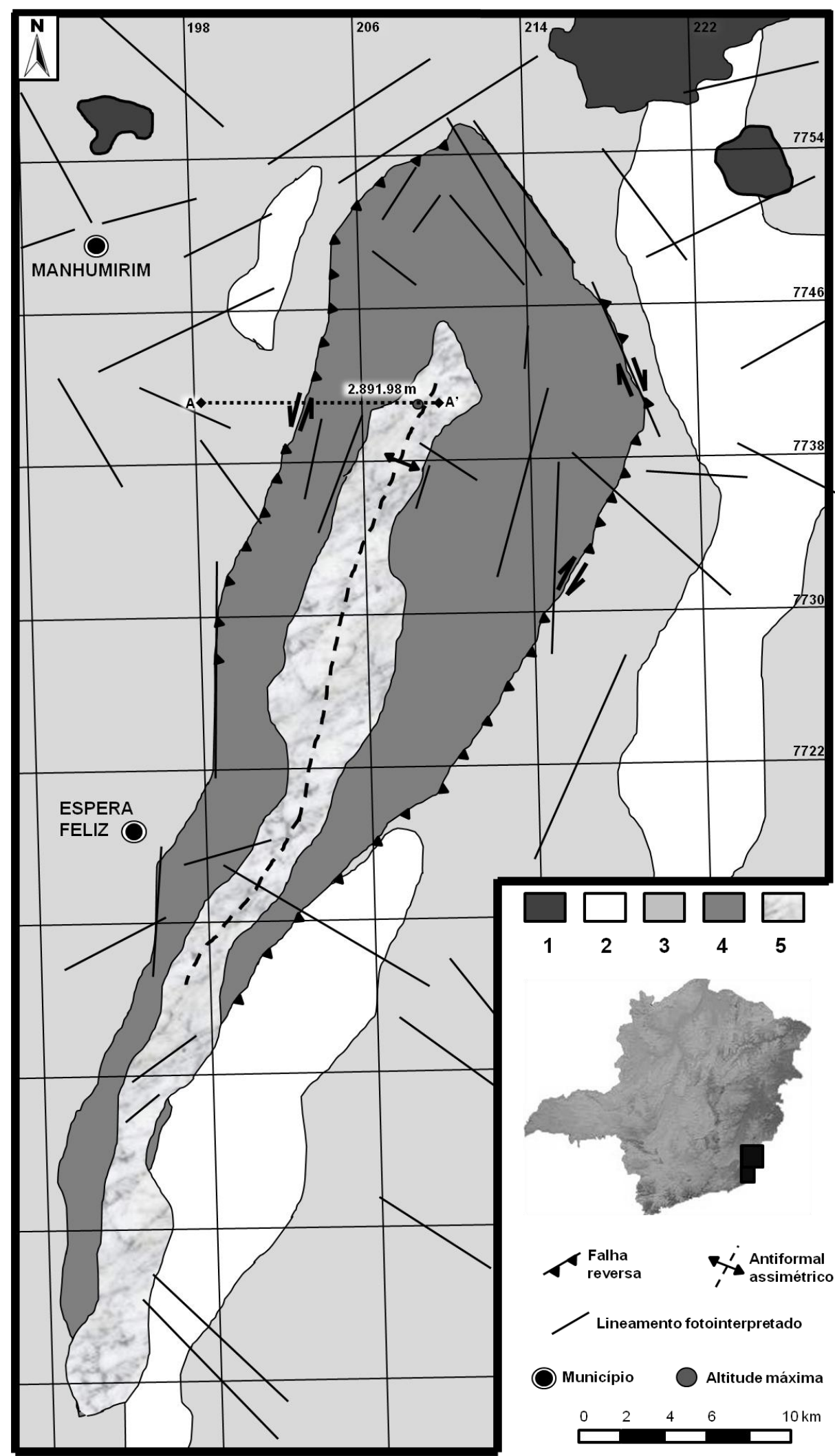

Figura 1. Mapa geológico da região da Serra do Caparaó. 1, granitóides não deformados; 2, granitóides deformados; 3, rochas metassedimentares neoproterozóicas; 4, gnaisses granulíticos da Suíte Caparaó; 5, migmatitos da Suíte Caparaó. O perfil A-A' está representado na Figura 3.

Figure 1. Geological map of the Serra do Caparaó region. 1, non-deformed granitoids; 2, deformed granitoids; 3, Neoproterozoic metasedimentary rocks; 4, granulitic gneisses of the Caparaó Suite; 5, migmatites of the Caparaó Suite. Section A-A' shown in Figure 3. 


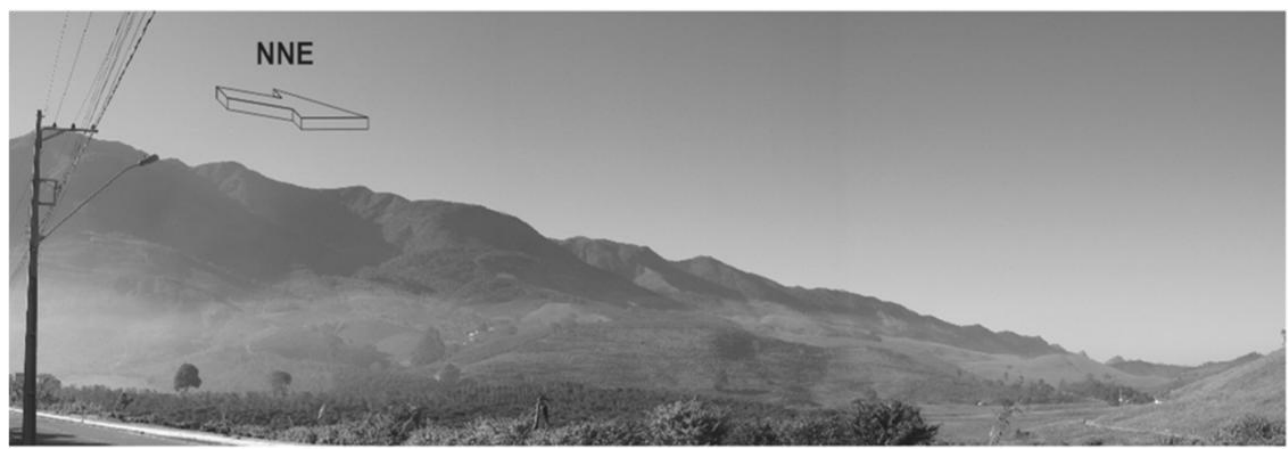

Figura 2. Paisagem da Serra do Caparaó, mostrando a linha de serra orientada a NNE, paralelamente à estruturação brasiliana.

Figure 2. Caparaó landscape, showing the NNE ridge orientation parallel to the Brasiliano structural trend.

\section{2 - GEOLOGIA DA SERRA DO CAPARAÓ}

Na Serra do Caparaó podem ser individualizadas três unidades maiores com relativa homogeneidade litológica: o embasamento, a cobertura metassedimentar neoproterozóica e os granitóides neoproterozóico-cambrianos (Noce et al. 2003, 2007a). O embasamento é representado pelos gnaisses granulíticos e migmatitos da Suíte Caparaó, os quais sustentam a serra homônima e, geralmente, mostram contatos tectônicos com a cobertura metassedimentar neoproterozóica (Fig. 1). A cobertura metassedimentar neoproterozóica é, essencialmente, constituída de paragnaisses migmatizados. Os granitóides foliados a gnaissificados são correlacionados com os estágios pré-colisional e sincolisional do Orógeno Araçuaí. Os granitóides livres da deformação regional são do tipo I e correlacionam-se ao plutonismo tardio, cambriano, do Orógeno Araçuaí (Pedrosa-Soares et al. 2011).

\subsection{Suíte Caparaó}

A maior exposição da Suíte Caparaó, na serra homônima, tem uma extensão de aproximadamente $300 \mathrm{~km} 2$ (Fig. 1). O conjunto rochoso e as feições geomorfológicas da serra seguem a orientação do bandamento gnáissico de direção NNE-NE (Fig. 2 e 3). O Pico da Bandeira foi esculpido sobre os migmatitos que dominam o núcleo da serra, a qual tem as bordas sustentadas pelos gnaisses granulíticos (Fig. 3).
O litotipo predominante na Suíte Caparaó é um gnaisse ortoderivado, bandado, diorítico a granítico, de granulação média a fina (Fig. 4A,B). Este gnaisse apresenta coloração esverdeada quando fresco, mudando para tons de cinza ao menor sinal de intemperismo. O bandamento, milimétrico a centimétrico, reflete a alternância composicional entre bandas mais claras, ricas em plagioclásio, quartzo e/ou feldspato potássico, com raro ortopiroxênio, e bandas mais máficas, constituídas de ortopiroxênio, hornblenda e biotita, com clinopiroxênio e plagioclásio subordinado. Os minerais acessórios são titanita, zircão, granada, apatita e opacos.

A foliação do ortognaisse é materializada pelo estiramento de quartzo, feldspato, piroxênio, anfibólio e biotita. Localmente, quartzo e feldspato formam mosaicos granoblásticos. A textura é essencialmente nematoblástica, salvo raras exceções onde a biotita predomina sobre anfibólio e piroxênio, dando à rocha uma textura lepidoblástica. Os cristais de piroxênio mostram uralitização fraca a moderada, gerando agregados de anfibólio e biotita. O plagioclásio apresenta intercrescimento antipertítico, fraca saussuritização e geminação polissintética (lei da albita) comumente interrompida ou recurvada como conseqüência da intensa deformação. A hornblenda tem coloração marrom a castanho, indicando enriquecimento em titânio, confirmado pela associação com titanita.

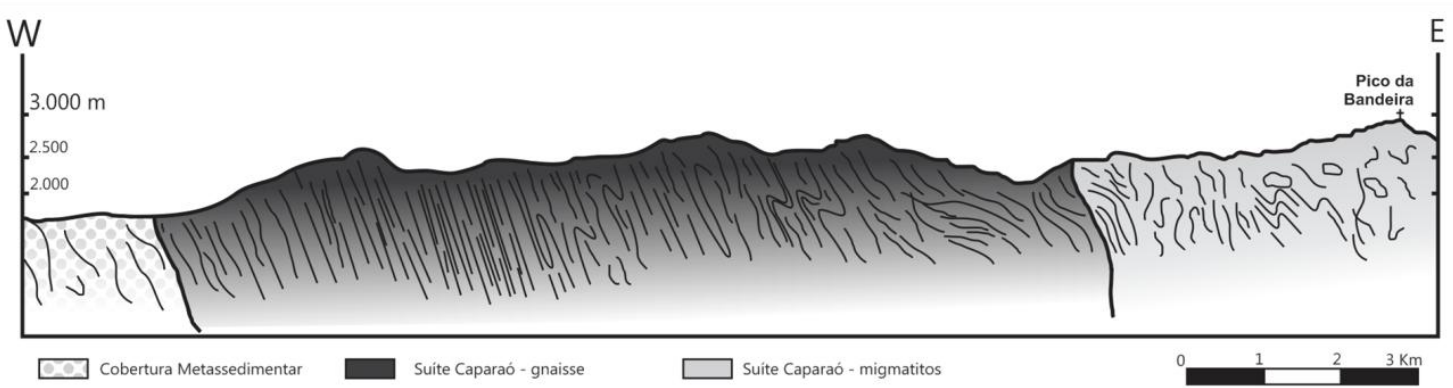

Figura 3. Perfil geológico na parte noroeste da Serra do Caparaó ( $A-A^{\prime}$ indicado na Figura 1).

Figure 3. Geological section across the northwestern part of the Caparaó ridge (A-A' located in Figure 1). 
O feldspato potássico é o ortoclásio que apresenta intercrescimento pertítico e sericitização incipiente. No contato entre plagioclásio e feldspato potássico ocorre intercrescimento de quartzo vermiforme (mirmequita). O quartzo apresenta forte extinção ondulante, feições de recristalização metamórfica e formação de subgrãos. Comumente os feldspatos e o quartzo apresentam fraturas preenchidas por material micáceo.

O ortognaisse da Suíte Caparaó exibe encraves máficos centimétricos a métricos, boudinados na direção do bandamento (Fig. 4B). Estes encraves têm cor cinza escura esverdeada (em superfície fresca) e estrutura maciça. Sua granulação é fina a muito fina e a textura é granoblástica. A associação mineralógica essencial é dada por plagioclásio, ortopiroxênio e clinopiroxênio, caracterizando a fácies granulito. Assim como o ortognaisse, os encraves apresentam biotita e hornblenda, oriundas da alteração dos piroxênios, em paragênese regressiva da fácies anfibolito.

No contato com outras unidades da área, o ortognaisse da Suíte Caparaó desenvolve textura milonítica caracterizada por fitas (ribbons) de quartzo e porfiroclastos sigmoidais.

A unidade migmatítica da Suíte Caparaó mostra intensidades diversas de fusão parcial. As principais estruturas migmatíticas são schlieren, ptigmática e estromática, mas agmática, dobrada e flebítica também ocorrem (Fig. 4C). Os migmatitos da Suíte Caparaó apresentam composição mineralógica essencial dada por quartzo, feldspato potássico, plagioclásio, ortopiroxênio, hornblenda, biotita e clinopiroxênio, em ordem decrescente de abundância. Os minerais acessórios são apatita, titanita, zircão e opacos. A textura é predominantemente granoblástica, materializada por mosaicos compostos essencialmente por quartzo e feldspato, com ortopiroxênio, hornblenda e biotita subordinados.

O leucossoma do migmatito tem composição granítica e granulação grossa. Apresenta cristais de anfibólio e piroxênio de até $3 \mathrm{~cm}$ na maior dimensão. Comumente exibe textura porfirítica a porfiroclástica, com cristais de feldspato de até $7 \mathrm{~cm}$ na maior dimensão. O melanossoma possui composição tonalítica e granulação fina a média, é rico em piroxênios, hornblenda e plagioclásio, com feldspato potássico, quartzo e biotita ocorrendo em menor quantidade. Localmente, observam-se restos do ortognaisse bandado que representa $o$ paleossoma do migmatito, envoltos e cortados por neossoma. Encraves máficos, com formas irregulares a elipsoidais, estão distribuídos de forma aleatória no migmatito.
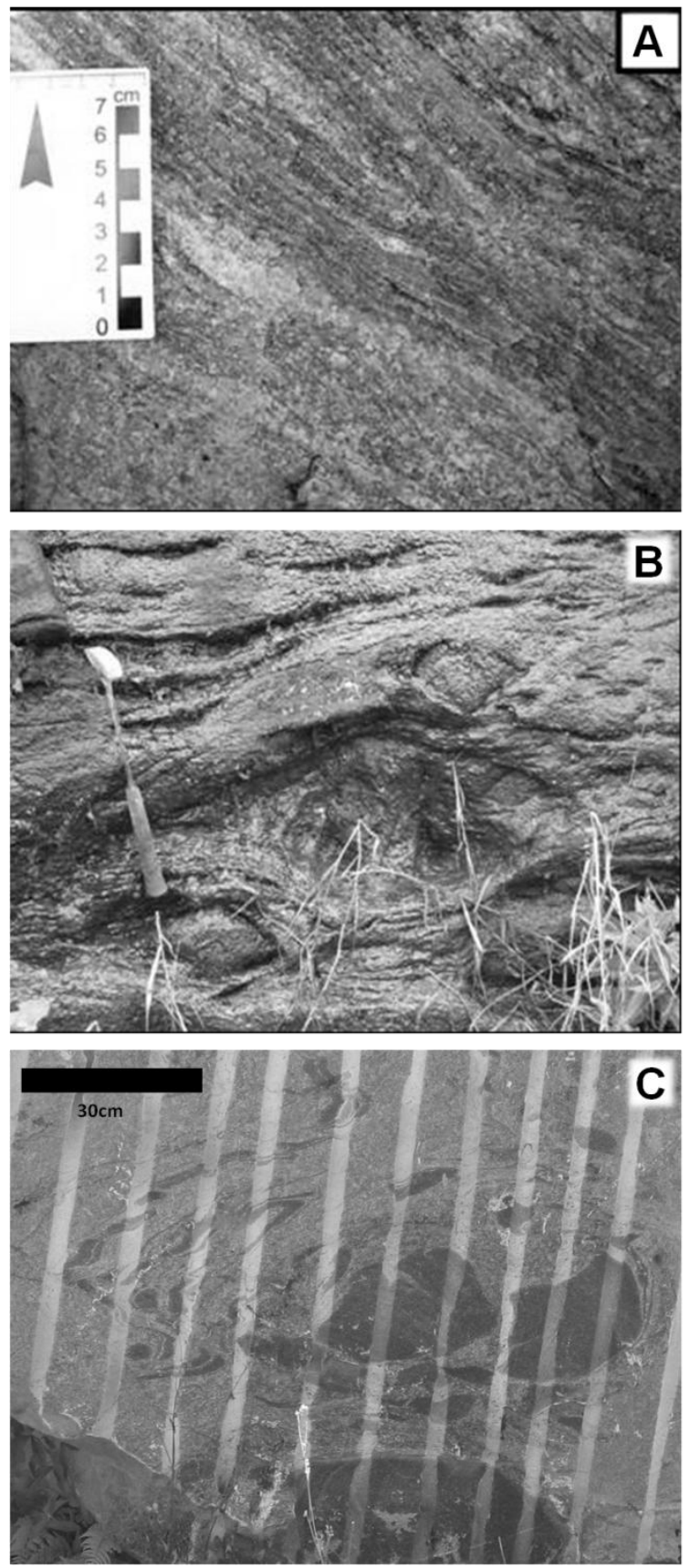

Figura 4. Rochas da Suíte Caparaó: $A$, ortognaisse granulítico bandado; $B$, encraves máficos, boudinados segundo a foliação regional do ortognaisse; $C$, migmatito agmático (as listras claras $e$ paralelas destacam sulcos de perfuração para extração de rocha ornamental).

Figure 4. Rocks from the Caparaó Suite: $A$, banded granulitic orthogneiss; $B$ ) boudins of mafic enclaves stretched along the regional foliation of the orthogneiss; C) agmatic migmatite (the parallel, light colored stripes are from holes for dimension stone exploitation). 


\section{3 - GEOLOGIA ESTRUTURAL E METAMORFISMO}

A Suíte Caparaó possui uma gama de estruturas geradas em regime deformacional dúctil. A foliação, paralela ao bandamento composicional, é a estrutura mais proeminente. Tem direção predominante a NNE, com mergulhos altos (valores modais entre $60^{\circ}$ e $85^{\circ}$ ), ora para oeste ora para leste, com deflexões locais para mergulho médio a baixo e vertical (Fig. 5A). Macroscopicamente, pode ser observável uma lineação mineral e de estiramento marcada, principalmente, por cristais de quartzo, feldspato potássico e plagioclásio estirados, contida na foliação principal. Há pouca variação na obliqüidade da lineação, que geralmente é downdip, em relação à foliação que a contém (Fig. 5B).

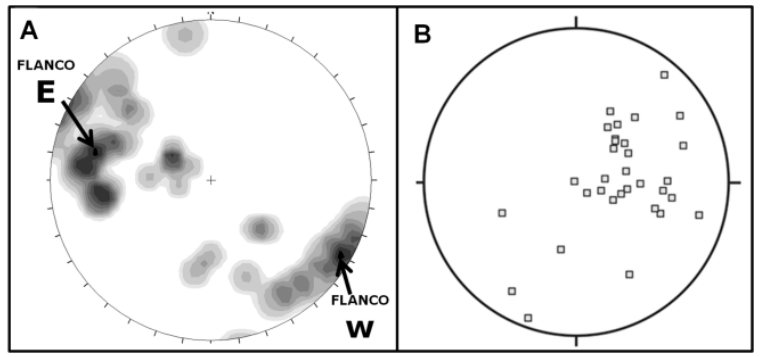

Figura 5. Diagrama de contorno de pólos para a foliação do ortognaisse da Suíte Caparaó (A) e diagrama de pólos da lineação de estiramento mineral (B).

Figure 5. Pole contour diagram for the foliation of the Caparao orthogneiss $(A)$ and pole diagram for the mineral stretching lineation (B).

Próximo a contatos tectônicos, os litotipos da Suíte Caparaó comumente adquirem textura milonítica a ultramilonítica. As principais feições deformacionais desenvolvidas nestas zonas são porfiroclastos ocelares com sombra de pressão e calda de recristalização. Comumente, os cristais de feldspato e quartzo apresentam extinção ondulante, desenvolvimento de subgrãos e evidências de recristalização dinâmica. O quartzo ocorre também em fitas (ribbons) estiradas na foliação principal. O plagioclásio exibe geminação recurvada e/ou interrompida. A partir da análise dos indicadores cinemáticos, relacionados à foliação e lineação de estiramento nela contida, conclui-se que o transporte tectônico se deu por cavalgamento de SE para NW.

A Suíte Caparaó apresenta um amplo acervo de dobras, tanto abertas quanto fechadas, decimétricas a decamétricas, assimétricas, com vergência geral para NW. Estas dobras apresentam eixo com orientação geral NNE a N-S e caimentos variados. As dobras que apresentam geometria simétrica são abertas e de grandes dimensões.

Devido a seu caráter reológico muito resistente e dimensão avantajada, a Suíte Caparaó modelou as estruturas ao seu redor. Desta forma, a Serra do Caparaó expõe uma lasca tectônica moldada em antiformal de proporções quilométricas, assimétrico, muito apertado, com plano axial aproximadamente vertical. $O$ flanco oeste foi parcialmente invertido (Fig. 3), mas, no conjunto geral, o mega-antiformal do Caparaó tem flanco oeste mergulhante para WNW (300/85 $)$ e flanco leste para ESE (110/70 ${ }^{\circ}$, Fig. $5 A)$. A parte invertida do flanco oeste exibe dobras parasíticas em $Z$ e zonas de cisalhamento reversas invertidas (Fig. 3 e 4A). A serra é circundada por zonas de cisalhamento reversas de alto ângulo. $\mathrm{Na}$ borda leste da Serra do Caparaó, a zona de cisalhamento inversa apresenta componente transcorrente destral, enquanto que na borda oeste o componente transcorrente é sinistral (Fig. 1). A zona de charneira do antiformal da Serra do Caparaó é marcada por intensa migmatização e sustenta o Pico da Bandeira.

A paragênese composta por plagioclásio + quartzo + hiperstênio \pm feldspato potássico \pm clinopiroxênio é comum aos gnaisses e migmatitos da Suíte Caparaó, indicando que ambos atingiram condições de estabilidade na fácies granulito do metamorfismo regional progressivo. Entretanto, esta paragênese progressiva de alto grau foi parcialmente desestabilizada por hidratação, gerando uma paragênese regressiva marcada pela significativa presença de hornblenda e biotita como produtos da alteração dos piroxênios. Este metamorfismo regressivo ocorreu na fácies anfibolito.

\section{4 - LITOQUÍMICA}

Embora a quantidade de dados seja insuficiente para se elaborar uma análise estatística, as quatro amostras analisadas servem a uma abordagem preliminar sobre a litoquímica da Suíte Caparaó (Tabela 1). Amostrou-se um ortognaisse e seu encrave máfico, e duas bandas escuras que parecem representar partes do paleossoma do migmatito.

A composição química das amostras da Suíte Caparaó varia de gabróica (encrave máfico do ortognaisse), diorítica (ortognaisse) e gabrodiorítica a monzodiorítica (bandas escuras do migmatito) (Fig. 6A). No diagrama AFM, o ortognaisse e seu encrave máfico indicam série cálcio-alcalina e as bandas escuras do migmatito sugerem tendência toleiítica (Fig. 6B). O encrave máfico cai no campo de médio potássio e o ortognaisse no de alto potássio das séries cálcio-alcalinas (Fig. 6C). As bandas escuras do migmatito também mostram variação marcante no conteúdo de potássio, mas isto pode refletir influência do processo de fusão parcial (aliás, como outras características químicas destas bandas). 0 ortognaisse, seu encrave máfico e uma amostra do migmatito mostram atributos químicos similares aos 
principais campos composicionais do Complexo Juiz de Fora (Fig. 6).

Tabela 1. Dados litoquímicos de amostras da Suíte Caparaó. Elementos maiores em \% peso, traços e elementos terras raras (ETR) em ppm. P.F., perda ao fogo.

\begin{tabular}{|c|c|c|c|c|}
\hline & $\begin{array}{c}\text { encrave } \\
\text { máfico } \\
(G 022 B)\end{array}$ & $\begin{array}{c}\text { ortognaisse } \\
\text { (GB124) }\end{array}$ & $\begin{array}{c}\text { banda } \\
\text { escura de } \\
\text { migmatito } \\
\text { (G011) }\end{array}$ & $\begin{array}{c}\text { banda } \\
\text { escura de } \\
\text { migmatito } \\
\text { (G025) }\end{array}$ \\
\hline \multicolumn{5}{|l|}{ Maiores } \\
\hline $\mathrm{SiO}_{2}$ & 50,60 & 62,00 & 53,16 & 52,17 \\
\hline $\mathrm{TiO}_{2}$ & 1,04 & 1,21 & 1,72 & 1,91 \\
\hline $\mathrm{Al}_{2} \mathrm{O}_{3}$ & 16,21 & 14,73 & 16,83 & 13,62 \\
\hline $\mathrm{Fe}_{2} \mathrm{O}_{3} \mathrm{t}$ & 8,76 & 8,22 & 10,77 & 16,72 \\
\hline $\mathrm{MnO}$ & 0,14 & 0,06 & 0,19 & 0,37 \\
\hline $\mathrm{MgO}$ & 8,01 & 3,08 & 3,17 & 4,24 \\
\hline $\mathrm{CaO}$ & 9,35 & 3,01 & 6,50 & 8,36 \\
\hline $\mathrm{Na}_{2} \mathrm{O}$ & 3,24 & 2,95 & 3,19 & 2,45 \\
\hline $\mathrm{K}_{2} \mathrm{O}$ & 1,20 & 3,62 & 2,32 & 0,35 \\
\hline $\mathrm{P}_{2} \mathrm{O}_{5}$ & 0,21 & 0,16 & 0,85 & 0,25 \\
\hline P.F. & 0,90 & 0,50 & 0,80 & 0,70 \\
\hline SOMA & 99,67 & 99,55 & 99,50 & 99,75 \\
\hline \multicolumn{5}{|l|}{ Tracos } \\
\hline $\mathrm{Ba}$ & 351 & 1488 & 1812 & 200 \\
\hline $\mathrm{Rb}$ & 38 & 125,5 & 54,4 & 2,6 \\
\hline $\mathrm{Sr}$ & 416 & 319,5 & 918,6 & 218,6 \\
\hline$Y$ & 24,5 & 8,5 & 30,5 & 45,5 \\
\hline $\mathrm{Zr}$ & 119,3 & 550,7 & 221,7 & 122,8 \\
\hline $\mathrm{Nb}$ & 15,5 & 21,5 & 14,3 & 6,2 \\
\hline Th & 3,3 & 13,9 & 5,1 & 0,2 \\
\hline $\mathrm{Pb}$ & 0,8 & 1,4 & 1,5 & 0,4 \\
\hline Ga & 15,6 & 23 & 21 & 21,2 \\
\hline $\mathrm{Zn}$ & 30 & 78 & 85 & 19 \\
\hline $\mathrm{Cu}$ & 48,6 & 18,9 & 25,1 & 59,8 \\
\hline $\mathrm{Ni}$ & 42,3 & 40,5 & 10,1 & 10,5 \\
\hline $\mathrm{V}$ & 177 & 53 & 172 & 360 \\
\hline $\mathrm{Cr}$ & 44 & 15 & 20 & 40 \\
\hline $\mathrm{Hf}$ & 3,1 & 16,4 & 5,5 & 3,6 \\
\hline Cs & 1 & 0,4 & 0,7 & 0,1 \\
\hline $\mathrm{Sc}$ & 31 & 13 & 18 & 46 \\
\hline Co & 75,4 & 98,3 & 51,2 & 78,1 \\
\hline $\mathrm{Li}$ & 83 & 52 & 20 & 20 \\
\hline $\mathrm{Be}$ & 1 & 1 & 1 & 1 \\
\hline$U$ & 1,1 & 0,5 & 1,1 & 0,1 \\
\hline W & 194,4 & 469,8 & 160,8 & 186,3 \\
\hline \multicolumn{5}{|l|}{ ETR } \\
\hline $\mathrm{La}$ & 21,4 & 69,5 & 53,5 & 10,5 \\
\hline $\mathrm{Ce}$ & 42,9 & 138,4 & 122,9 & 28,3 \\
\hline $\mathrm{Pr}$ & 5,51 & 16,23 & 15,74 & 4,29 \\
\hline $\mathrm{Nd}$ & 21,9 & 59,9 & 63,1 & 21,2 \\
\hline Sm & 4,62 & 8,21 & 10,74 & 5,52 \\
\hline Eu & 1,43 & 1,86 & 2,46 & 1,76 \\
\hline $\mathrm{Gd}$ & 4,38 & 5,32 & 8,61 & 6,54 \\
\hline $\mathrm{Tb}$ & 0,78 & 0,51 & 1,20 & 1,28 \\
\hline Dy & 4,06 & 2,11 & 6,19 & 7,78 \\
\hline Ho & 0,88 & 0,29 & 1,05 & 1,71 \\
\hline $\mathrm{Er}$ & 2,47 & 0,85 & 3,04 & 5,10 \\
\hline $\mathrm{Tm}$ & 0,39 & 0,12 & 0,43 & 0,75 \\
\hline $\mathrm{Yb}$ & 2,41 & 0,89 & 2,39 & 4,57 \\
\hline Lu & 0,37 & 0,14 & 0,35 & 0,70 \\
\hline
\end{tabular}
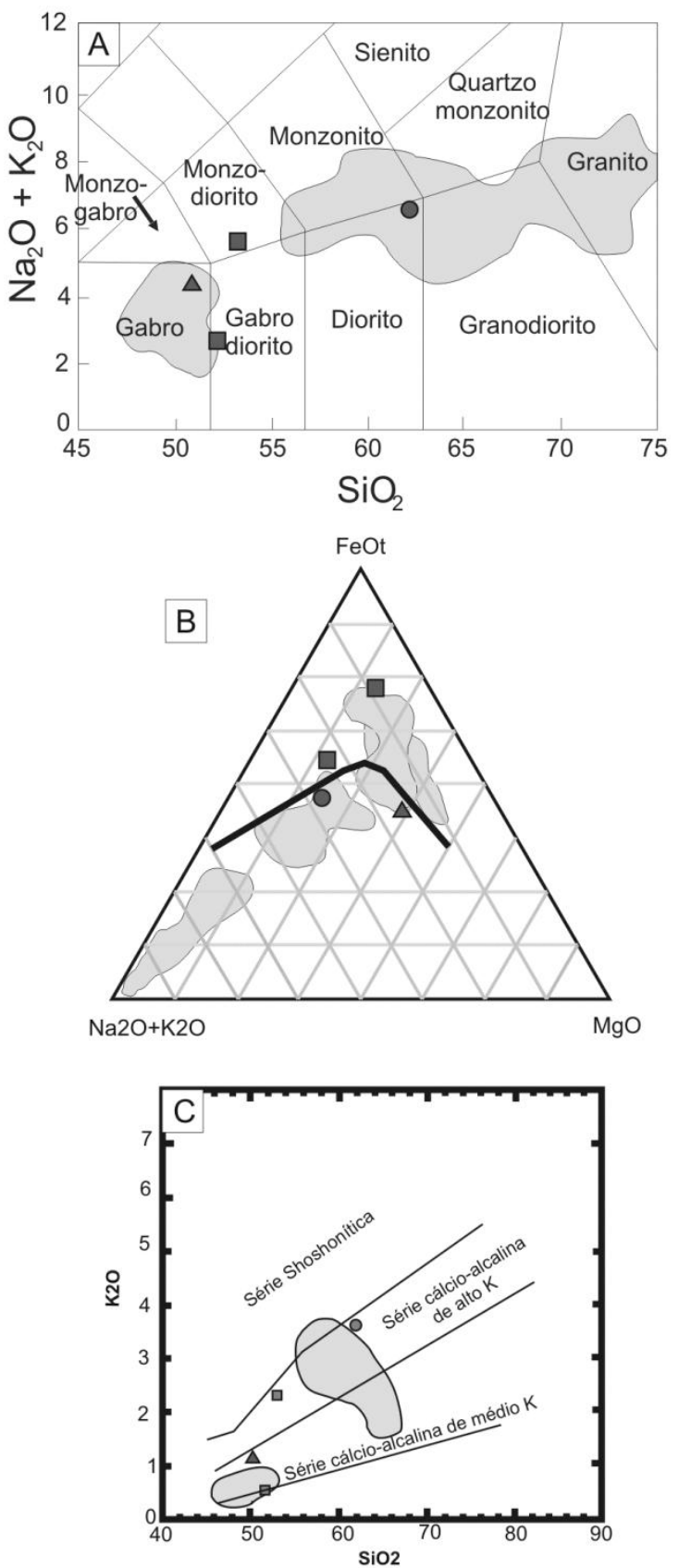

Figura 6: Representação de atributos litoquímicos de amostras de ortognaisse (círculo), encrave máfico (triângulo) e bandas escuras de migmatito (quadrado) da Suíte Caparaó nos diagramas (A) TAS de (Wilson 1989, Xianhua et al. 2000), (B) AFM (Jensen 1976) e (C) séries cálcio-alcalinas (Rickwood 1989, Le Maitre et al. 1989). As

áreas sombreadas correspondem aos principais campos composicionais de rochas do Complexo Juiz de Fora (cf. Novo 2009, Novo et al. 2010, e referências aí citadas).

Figure 6: Litochemical data from samples of orthogneiss (circle), mafic enclave (triangle) and migmatite dark bands (square) of the Caparaó Suite plotted in (A) TAS diagram (Wilson 1989, Xianhua et al. 2000), (B) AFM diagram (Jensen 1976) and (C) calc-alkaline series diagram (Rickwood 1989, Le Maitre et al. 1989). Shaded areas correspond to the major compositional fields of the Juiz de Fora Complex (cf. Novo 2009, Novo et al. 2010, and references therein). 
A morfologia das curvas das amostras de ortognaisse e migmatito, no diagrama de elementos terras raras, é muito semelhante e pode indicar algum parentesco genético (Fig. 7A). O encrave máfico é mais pobre em terras raras pesadas, mas a morfologia geral da curva é similar às demais. No geral, as curvas de terras raras destas amostras se assemelham a padrões de uma suíte cálcio-alcalina expandida. As amostras analisadas mostram um conjunto similar a rochas comuns do Complexo Juiz de Fora, embora algo mais enriquecido em terras raras leves (Fig. 7B).
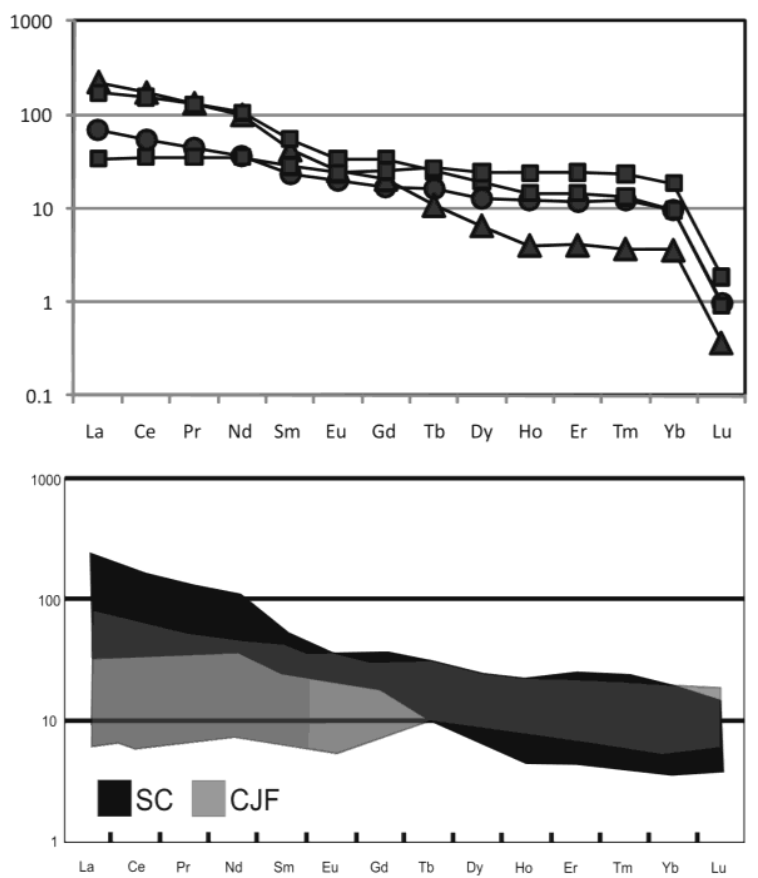

Figura 7. Padrões de elementos terras raras de amostras de ortognaisse (círculo), encrave máfico (triângulo) e bandas escuras de migmatito (quadrado) da Suíte Caparaó ( $A$ ), também representados (B) em comparação ao Complexo Juiz de Fora (CJF, faixa cinza sobreposta; SC, Suíte Caparaó), normalizados em relação a condrito (Taylor \& McLennan 1985).

Figure 7. Rare earth element patterns for samples of orthogneiss (circle), mafic enclave (triangle) and migmatite dark bands (square) of the Caparaó Suite (A), also shown in comparison (B) to the Juiz de Fora Complex (CJF, superimposed shaded area; SC, Caparaó Suíte), normalized to chondrite (Taylor \& McLennan 1985).

\section{5 -CONCLUSÃO}

A Suíte Caparaó é exclusivamente constituída por ortognaisses e migmatitos, ambos ortoderivados, que exibem metamorfismo progressivo, sincinemátcio à foliação relacionada aos empurrões regionais, na fácies granulito.

As intercalações metassedimentares regionalmente incluídas na Suíte Caparaó por outros autores (e.g., Söllner et al. 1991, Seidensticker \& Wiedemann 1992) pertencem, de fato, à cobertura neoproterozóica (Grupo Andrelândia; e.g., Noce et al. 2003, 2007a; Horn et al. 2006; Novo 2009; Novo et al. 2010).

A grande similaridade petrográfica e litoquímica do ortognaisse da Suíte Caparaó com o litotipo clássico do Complexo Juiz de Fora, um ortopiroxênio-hornblenda ortognaisse (Duarte et al., 1997; Noce et al. 2003, 2007a, 2007b), sugere a correlação entre estas unidades. Entretanto, a idade de $2195 \pm 15$ Ma obtida para a cristalização magmática da Suíte Caparaó (U-Pb SHRIMP em zircão, Silva et al. 2002) é cerca de $75 \mathrm{Ma}$ mais antiga que a maior idade de cristalização magmática (2119 $\pm 16 \mathrm{Ma})$ do Complexo Juiz de Fora na região a oeste da Serra do Caparaó (U-Pb SHRIMP em zircão, Noce et al. 2007b). Contudo, na região logo a sul, em terrenos da Faixa Ribeira, idade de cristalização magmática em torno de 2199 Ma foi obtida de rocha do Complexo Juiz de Fora (Heilbron et al. 2010), viabilizando assim uma correlação mais consistente entre a Suíte Caparaó e este complexo.

\section{6 -AGRADECIMENTOS}

Os autores agradecem a FAPEMIG (bolsa de doutorado do primeiro autor), CNPq (bolsas de produtividade e auxílios financeiros concedidos a C.M. Noce e A.C. Pedrosa Soares), CPRM-Serviço Geológico do Brasil pelos contratos firmados com a UFMG para mapeamento geológico pelo Programa Geologia do Brasil; e aos revisores anônimos de Geonomos.

\section{7 - REFERÊNCIAS BIBLIOGRÁFICAS}

Campos Neto M.C. \& Figueiredo M.C.H. 1990. Evolução geológica dos terrenos Costeiro, Paraíba do Sul e Juiz de Fora (RJ-MGES). In: Congresso Brasileiro de Geologia, 36, Anais, Natal: 6: 2631-2648.

Duarte B., Figueiredo M., Campos Neto, M.; Heilbron M. 1997. Geochemistry of granulite facies orthgneisses of the Juiz de Fora Complex, central segment of the Ribeira Belt, Southeastern Brazil. Revista Brasileira de Geociências, 21(1): 67-82.

Gatto L.C.S., Ramos V.L.S., Nunes B.T.A., Mamede L., Góes M.H.B., Mauro C.A., Alvarenga S. M., Franco E. M. S., Quirico A. F., Neves L. B. 1983. Geomorfologia. In: Projeto RADAMBRASIL, Folhas SF.23/24 Rio de Janeiro/Vitória; geologia, geomorfologia, pedologia, vegetação e uso potencial da terra, Rio de Janeiro, IBGE, p. 305-384.

Heilbron M.L., Pedrosa-Soares A.C., Campos Neto M.C., Silva L.C., Trouw R. \& Janasi V.A. 2004. Província Mantiqueira. In: V.M. Mantesso-Neto A. Bartorelli C.D.R. Carneiro, Brito-Neves, B.B. (orgs.). Geologia do Continente Sul-Americano, Editora Beca, p. 203-234.

Heilbron M., Duarte B., Valeriano C., Simonetti A., Machado N., Nogueira J. 2010. Evolution of reworked Paleoproterozoic basement rocks within the Ribeira belt (Neoproterozoic), SEBrazil, based on $\mathrm{U}-\mathrm{Pb}$ geochronology: Implications for paleogeographic reconstructions of the São Francisco-Congo paleocontinent. Precambrian Research, 178: 136-148. 
Horn A.H. 2006. Geologia da Folha Espera Feliz 1:100.000. Rio de Janeiro, CPRM/UFMG - Programa Geologia do Brasil.

IBGE 2004. Notícias. Quatro picos brasileiros têm sua altitude alterada. www.ibge.gov.br

Jensen L.S. 1976. A new cation plot for classifying subalkaline volcanic rocks. Ontario Division of Mines, Miscellaneous, 66p.

Le Maitre R.W. 1989. A Classification of Igneous Rocks and Glossary of Terms. Oxford, Blackwell, $193 \mathrm{p}$.

Noce C.M., Romano A.W., Pinheiro C.M., Mol V.S., Pedrosa-Soares A.C. 2003. Geologia das Folhas Ubá e Muriaé. In: Projeto Sul de Minas - Etapa I: Geologia e Recursos Minerais do Sudeste Mineiro, Belo Horizonte, COMIG/UFMG/UFRJ/UERJ, cap. 12, p. 623-659.

Noce C.M., Costa A.G., Piuzana D., Vieira V.S. \& Carvalho C. 2007 a. Geologia da Folha Manhuaçu 1:100.000. Rio de Janeiro, CPRM/UFMG - Programa Geologia do Brasil.

Noce C.M., Pedrosa-Soares A.C., Silva L.C., Armstrong R. \& Piuzana, D. 2007b. Evolution of polyciclic basement complexes in the Araçuaí orogen, based on U-Pb SHRIMP data: Implications for Brazil-Africa links in Paleoproterozoic time. Precambrian Research, 159: 60-78.

Novo T. 2009. Significado geotectônico das rochas charnockíticas da região de Carangola: implicações para a conexão AraçuaíRibeira. Instituto de Geociências, Universidade Federal de Minas Gerais, Dissertação de Mestrado, 87 p.

Novo T.A., Pedrosa-Soares, A.C., Noce C.M., Alkimim F.F., Dussin I. 2010. Rochas charnockíticas do sudeste de Minas Gerais: a raiz granulítica do arco magmático do Orógeno Araçuaí. Revista Brasileira de Geociências, 40(4): 573-592.

Pedrosa-Soares A.C., Noce C.M., Wiedemann C.M. \& Pinto C.P. 2001. The Araçuaí-West Congo orogen in Brazil: An overview of a confined orogen formed during Gondwanland assembly. Precambrian Research, 110: 307-323.

Pedrosa-Soares A.C., Noce C.M., Alkmim F.F., Silva L.C., Babinski M., Cordani U., Castañeda C. 2007. Orógeno Araçuaí: síntese do conhecimento 30 anos após Almeida 1977. Geonomos, 15: $1-16$.
Pedrosa-Soares A.C., De Campos C., Noce C.M., Silva L.C., Novo T., Roncato J., Medeiros S., Castañeda C., Queiroga G., Dantas E., Dussin I., Alkmim F.F. 2011. Late NeoproterozoicCambrian granitic magmatism in the Araçuaí orogen (Brazil), the Eastern Brazilian Pegmatite Province and related mineral resources. Geological Society, London, Special Publications, 350: 25-51.

Rickwood P.C. 1989. Boundary lines within petrologic diagrams which use oxides of major and minor elements. Lithos, 22: 247-263.

Seidensticker U. \& Wiedemann C.M. 1992. Geochemistry and origin of lower crustal granulite facies rocks in the Serra do Caparaó region, Espírito Santo/Minas Gerais, Brazil. Journal South American Earth Sciences, 6: 289-298.

Silva L.C., Armstrong R, Noce C.M., Carneiro M., Pimentel M., Pedrosa-Soares A.C., Leite C., Vieira V. S., Silva M., Paes V. \& Cardoso-Filho J. 2002. Reavaliação da evolução geológica em terrenos pré-cambrianos brasileiros com base em novos dados U-Pb SHRIMP, parte II: Orógeno Araçuaí, Cinturão Móvel Mineiro e Cráton São Francisco Meridional. Revista Brasileira de Geociências, 32: 513-528.

Silva L.C., McNaughton N.J., Armstrong R., Hartmann L. \& Fletcher I. 2005. The Neoproterozoic Mantiqueira Province and its African connections. Precambrian Research, 136: 203-240.

Söllner F., Lammerer B., Weber-Diffenback K. 1991. Die krustenentwiclkung nordlich von Rio de Janeiro/Brasilien. 4 ed. Munique, Munchner Geologische. 100 p.

Taylor S.R. \& McLennan S.M. 1985. The Continental Crust, its composition and evolution; an examination of the geochemical record preserved in sedimentary rocks. Blackwell, Oxford. 312p.

Xinhua Z; Yin, A; Ryerson, F.J. 2000. The Zedong Window: A record of superposed Tertiary convergence in southeastern Tibet. Journal of Geophysical Research, 105: 19.211-19.230.

Wilson M. 1989. Igneous Petrogenesis. London, Unwin Hyman $470 p$ 